\title{
Comparison of Mechanical Properties of PEEK and PMMA: An In Vitro Study
}

\author{
Spardha P Shrivastava ${ }^{1}$, Rajani Dable ${ }^{2}$, AP Nirmal Raj $^{3}$, Puneet Mutneja ${ }^{4}$, Sparsh B Srivastava ${ }^{5}$, Merazul Haque ${ }^{6}$
}

\begin{abstract}
Aim: Evaluation and comparison of flexural strength and hardness of heat-cured polymethylmethacrylate (PMMA) denture base with polyetheretherketone (PEEK).

Material and methods: A total of 80 samples of PEEK and PMMA were prepared and divided into two groups: group A and group B, of 40 each. Both the groups were further divided into subgroups consisting of 20 samples of PMMA and PEEK. The group A specimens were tested for flexural strength by universal testing machine (UTM), and group B samples were subjected to hardness test using Vickers microhardness tester. The values obtained were subjected to statistical analysis. The readings were subjected to an unpaired t-test for comparison of flexural strength and hardness of PEEK and PMMA.

Result: The flexural strength of PEEK was $183 \mathrm{MPa}$, while that of PMMA was $84 \mathrm{MPa}$. The hardness of PEEK and PMMA was $24 \mathrm{VHN}$ and $19.4 \mathrm{VHN}$, respectively.

Conclusion: It was observed that PEEK can be a potential denture base material with superior properties as compared to PMMA. Further researches are needed to be carried out.

Clinical significance: PEEK as a denture base exhibits adequate flexural strength prolonging its clinical longevity and overcoming the most common reason for the failure of PMMA denture base that results in fracture.

Keywords: Flexural strength, Heat-activated PMMA, PEEK, Vickers microhardness test.

The Journal of Contemporary Dental Practice (2021): 10.5005/jp-journals-10024-3077
\end{abstract}

\section{INTRODUCTION}

Losing teeth as a result of accidents or diseases has proved to be troublesome to mankind throughout the ages. Adapting to the available contemporary materials for dental applications was necessary in an attempt to restore the function and appearance. As civilization advanced, there has been continuous development in both the quantity and quality of materials in order to obtain a material that is biocompatible, easy to manipulate, and control so as to make a prosthesis that is esthetically pleasing and also functionally effective. As it is correctly suggested that a sound foundation is required for a strong building, similarly a favorable denture base is needed for fabricating a successful denture. Various materials with newer properties have been put to use. ${ }^{1}$ Although in the timeline of the denture base, it is seen that the introduction of PMMA denture base can be considered as a milestone. ${ }^{2}$

The use of resins as denture base materials was initiated by Dr. Leo Bakeland in 1909 by using phenol formaldehyde resin. Because of its outstanding esthetics, easy processing, relining, and repair techniques, PMMA is still considered the most preponderant denture base material. Thus, the combination of these desirable properties makes it the material that is being widely used. ${ }^{3}$ It is seen that when this material is used as a denture base material, it is not perfect for everything, ${ }^{4}$ especially its mechanical properties. So as to surmount the limitations of PMMA, an advanced material PEEK has been introduced. It is a synthetically produced polymeric material that consists of a molecular chain of aromatic compound, and it is interconnected by ketone and ether functional groups. Initially, PEEK was introduced in the automobile and aerospace industries; but in 1990, a biomedical grade of PEEK was introduced for spinal and hip implants, and owing to its outstanding
${ }^{1}$ Department of Prosthodontics, Teerthanker Mahaveer Dental College, Moradabad, Uttar Pradesh, India; Awadh Dental College and Hospital, Jamshedpur, Jharkhand, India

4,6Department of Prosthodontics, Teerthanker Mahaveer Dental College, Moradabad, Uttar Pradesh, India

${ }^{5}$ Department of Orthodontics, Seema Dental College, Rishikesh, Uttarakhand, India

Corresponding Author: Spardha P Shrivastava, Department of Prosthodontics, Teerthanker Mahaveer Dental College, Moradabad, Uttar Pradesh, India; Awadh Dental College and Hospital, Jamshedpur, Jharkhand, India, Phone: +919035209702, e-mail: spardha02@gmail. com

How to cite this article: Shrivastava SP, Dable R, Nirmal Raj AP, et al. Comparison of Mechanical Properties of PEEK and PMMA: An In Vitro Study. J Contemp Dent Pract 2021;22(2):179-183.

Source of support: Nil

Conflict of interest: None

biological, chemical, thermal, and mechanical properties in 1999, PEEK was introduced to dentistry. The clinical longevity of any denture base material is evaluated by its water absorption ability, polymerization shrinkage, dimensional stability, and polishing ability. It is seen that PEEK absorbs less water than PMMA, even if it is immersed for 10 days at $121^{\circ} \mathrm{C}$. PEEK does not possess any shrinkage during processing, while around $2 \%$ of linear shrinkage and $7 \%$ of volumetric shrinkage is seen in PMMA. Hence, it can be said that PEEK remains chemically inert. ${ }^{5}$ However, information about its flexural strength and hardness as compared to heatcured PMMA is scarce. Flexural strength is basically the resiliency 
of the material under static loading. ${ }^{6}$ This study thus aims in evaluating and comparing the flexural strength and hardness of the heat-cured PMMA and PEEK.

\section{Materials and Methods}

This study was done in the Department of Prosthodontics and Crown and Bridge of Teerthanker Mahaveer Dental College and Research Center, Moradabad, in collaboration with Spectro Analytical Laboratory, Greater Noida, Uttar Pradesh, India, over a period of 2 years from 2017 to 2019. The heat-activated PMMA, Lucitone 199 (Dentsply), and PEEK, Sustapeek Röchling (Roechling), materials were used in this study along with Banbros computercontrolled universal testing system (Fig. 1) and MVK-H1 Vickers microhardness tester by MITUTOYO.

This study required 80 samples of which 40 specimens were PMMA and 40 were PEEK. Forty PMMA specimens were of dimensions $65 \times 10 \times 2.5 \mathrm{~mm}$ and were prepared in the department using a metal mold to get a uniform size of test specimens. Wax patterns were prepared followed by its processing according to the manufacturer's instructions. The final finishing and polishing of the specimens were done using silicon carbide paper of grit 80 and 240 sequentially along with pumice powder. The PEEK specimens of $65 \times 10 \times 2.5 \mathrm{~mm}$ were cut from biomedical grade PEEK sheets in the laboratory using a diamond saw cutter. The final dimension of the samples was verified using a vernier caliper. Only specimens of correct dimensions without any porosities were included in the study (Fig. 2). The final 80 specimens were divided into group $A$ of 40 PMMA specimens and group $B$ of 40 PEEK specimens. Group $A$ specimens were further subdivided into subgroups $A_{1}$ and $A_{2}$ of 20 PMMA and 20 PEEK specimens, respectively. Group $B$ specimens were subdivided into subgroup $B_{1}$ of 20 PMMA and subgroup $B_{2}$ of 20 PEEK specimens (Table 1). All the specimens were immersed in artificial saliva at $37^{\circ} \mathrm{C}$ for 30 days in a water bath.

\section{LABORATORY TESTS}

For 40 group A specimens, flexural strength was assessed by 3-point bending test. It is a strength test for a bar that is supported at both ends and is subjected to static loading in a UTM. The device consists of a loading wedge and a pair of adjustable supporting wedges placed at $50 \mathrm{~mm}$ apart. The specimen was centered on the

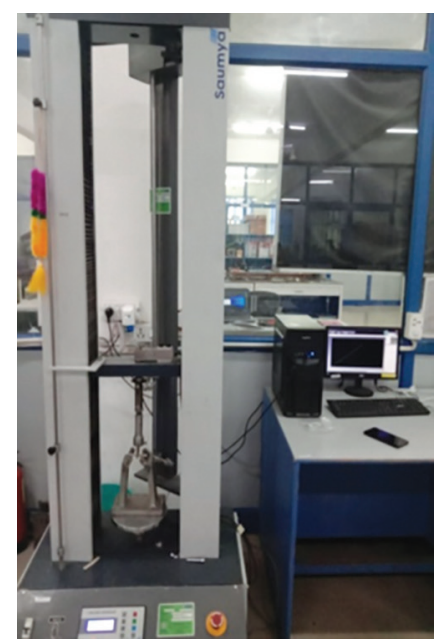

Fig. 1: Universal testing machine

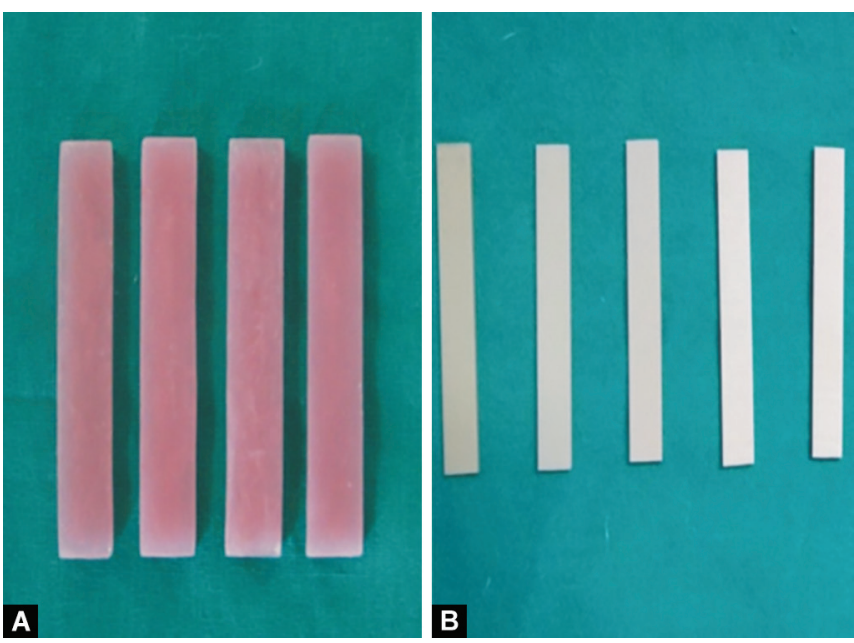

Figs. 2A and B: Prepared samples (A) PMMA and (B) PEEK

Table 1: Grouping of samples

\begin{tabular}{llll}
\hline Groups & Subgroups & Description & Specimens \\
\hline Group A & Group A1 & PMMA & 20 Specimens \\
(Flexural strength test) & Group A2 & PEEK & 20 Specimens \\
Group B & Group B1 & PMMA & 20 Specimens \\
(Hardness) & Group B2 & PEEK & 20 Specimens \\
\hline
\end{tabular}

device with the loading wedge, set to travel at a crosshead speed of $5 \mathrm{~mm} /$ minute with a $500 \mathrm{kgf}$ load cell, engaging the center of the upper surface of the specimen. The specimens were loaded. The subgroup $A_{1}$ specimens fractured after load application, while subgroup $A_{2}$ specimens showed significant bending. The peak load (fracture load) was recorded, and flexural strength was calculated (Fig. 3). For each specimen of both the subgroups, the transverse strength was calculated using the equation as follows:

$$
S=3 F I / 2 b d^{2}
$$

where $F$, peak force;

I, distance in between the supports $(50 \mathrm{~mm})$;

$b$, breadth of the sample; and

$d$, depth of the sample

For group B specimens, hardness was assessed by applying a force with a sharp point or an abrasive particle in order to form indentation. In this study, the Vickers microhardness test was done. In Vickers microhardness test, a square-based pyramid indenter is used for applying $300 \mathrm{~g}$ of load for 15 seconds. The specimen was kept at the table of the tester, and the specified load and dwell time were adjusted. The built-in microscope was used to observe the indentation made by the indenter on the surface of the specimen, and the hardness was calculated digitally based on the lengths of the diagonals. For each specimen, three indentations were made at least $1 \mathrm{~mm}$ from the previous indentation or the margins of the specimen. The mean of the three values obtained was considered as VHN for that specimen. For each specimen of both the subgroups, the values obtained were tabulated. Table 2 illustrates the flexural strength and VHN of the subgroups. The readings were subjected to statistical analysis in SPSS version 25.0 software. Unpaired $t$-test was utilized for comparison of the two means. The significance level for the statistical tests utilized in the study was predetermined at $p<0.05$. 

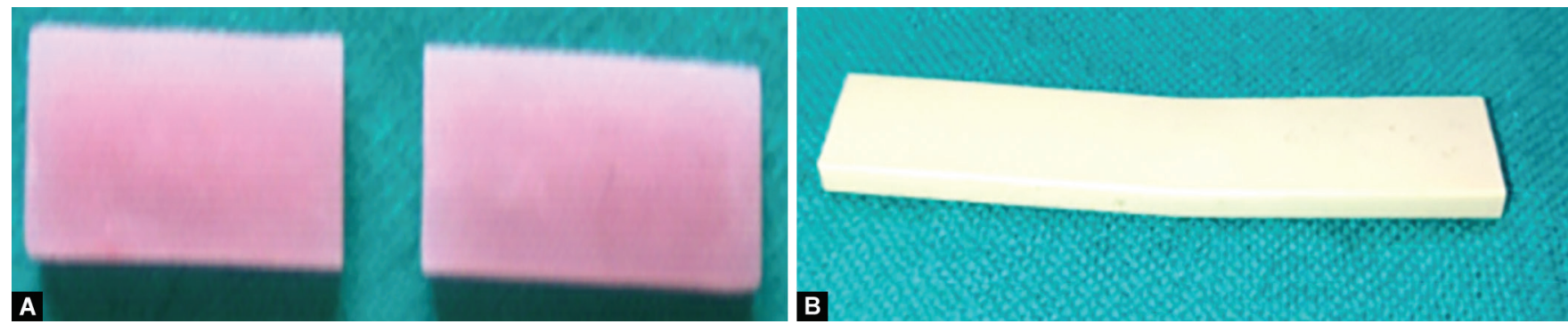

Figs. 3A and B: (A) Fractured PMMA specimen and (B) bent PEEK specimen

Table 2: Comparison of flexural strength and hardness of PMMA and PEEK specimens

\begin{tabular}{|c|c|c|c|c|c|}
\hline Groups & Mean & $S D$ & Mean difference & t-test value & $p$-value \\
\hline & \multicolumn{5}{|c|}{ Flexural strength (Mpa) } \\
\hline Subgroup A1 & 84.05 & 5.02 & -98.95 & -63.774 & $<0.001^{*}$ \\
\hline \multirow[t]{2}{*}{ Subgroup A2 } & 183.00 & 4.79 & & & \\
\hline & \multicolumn{5}{|c|}{ Hardness (VHN) } \\
\hline Subgroup B1 & 19.17 & 0.57 & -5.01 & -26.352 & $<0.001^{*}$ \\
\hline Subgroup B2 & 24.17 & 0.63 & & & \\
\hline
\end{tabular}

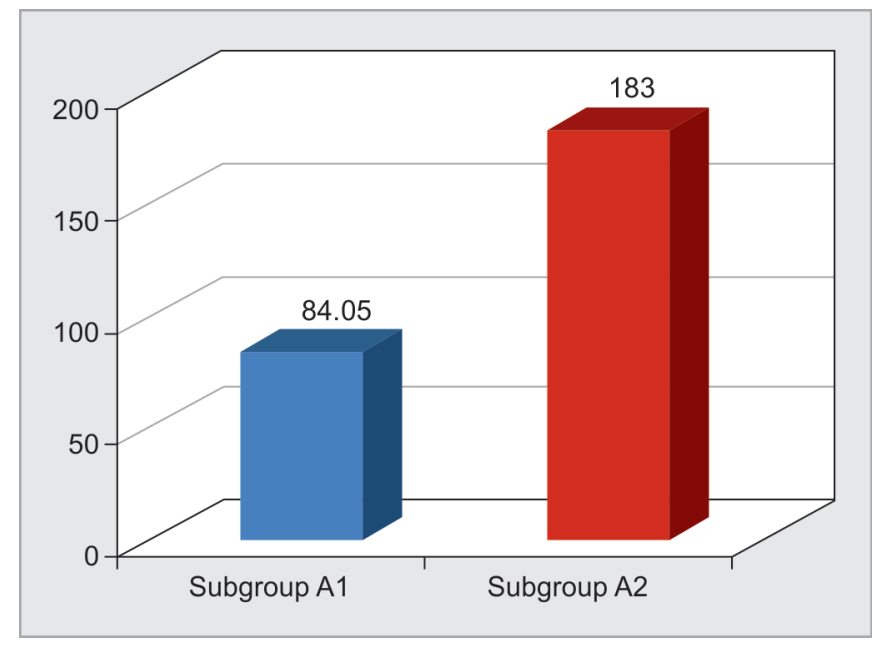

Graph 1: Comparison of flexural strength of PMMA (group $A_{1}$ ) and PEEK (group $\mathrm{A}_{2}$ ) specimens

\section{Results}

The mean flexural strength of all the specimens prepared with PMMA (subgroup $A_{1}$ ) was 84.05 Mpa with a standard deviation of 5.02 , whereas the mean flexural strength of PEEK (subgroup $A_{2}$ ) was 183.3 Mpa with a standard deviation of 4.79. The mean VHN of PMMA (subgroup $B_{1}$ ) was 19.17 with a standard deviation of 0.57 , whereas the mean VHN of PEEK (subgroup $B_{2}$ ) was 24.17 with a standard deviation of 0.63 . Table 2 shows the significant difference between the two subgroups (). The mean flexural strength (Mpa) significantly increased for subgroup $A_{2}$ as compared to subgroup $A_{1}$ with the " $p$ " value $<0.001$. VHN of the two subgroups $B_{1}$ and $B_{2}$ showed a significant difference with the $p$ value $<0.001$. Graph 1 shows the significantly higher flexural strength of the PEEK specimens (subgroup $A_{2}$ ), whereas Graph 2 shows the higher hardness exhibited by the PEEK specimens (subgroup $A_{2}$ ) as compared to the PMMA specimens.

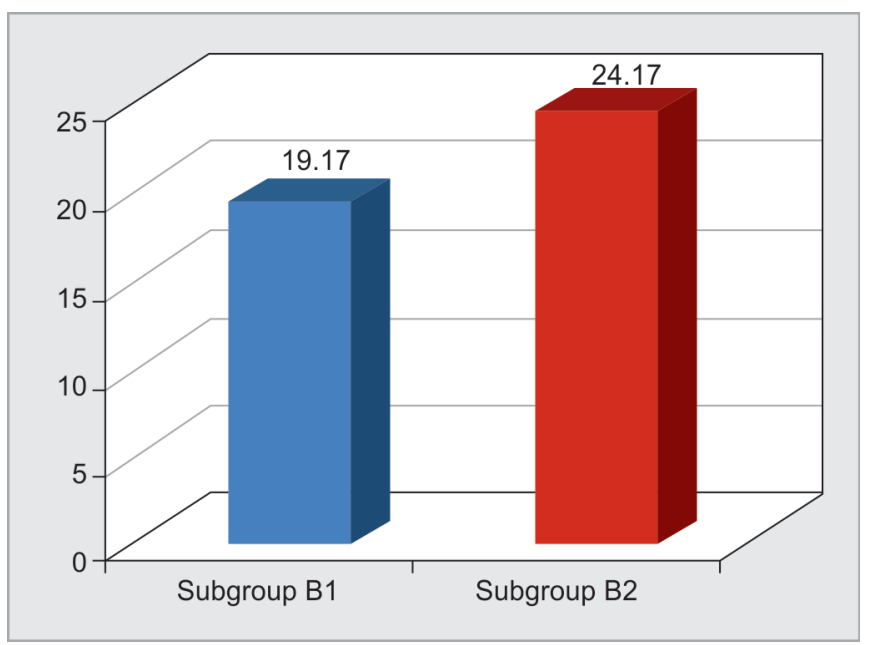

Graph 2: Comparison of the hardness of PMMA (group $B_{1}$ ) and PEEK (group $\mathrm{B}_{2}$ ) specimens

\section{Discussion}

Although acrylic resins were introduced to dentistry in $1937^{7}$ following which various materials have also been introduced in material science, none of them closely mimics the oral soft tissue as it does. Since its introduction, it is routinely and successfully being used for the fabrication of full and partial prosthesis owing to its outstanding properties. ${ }^{8}$ Studies done by Phoenix, ${ }^{9}$ Meng, and Latta ${ }^{10}$ suggested that PMMA is the most popularly used material for removable prosthodontics, but its low strength results in the failure of the prosthesis. Failures can result intraorally due to inadequate occlusion, excess bite force, unsatisfactory fit, or trauma and extraorally due to falling of the denture. ${ }^{11}$ In a study done by Beyli and Von Fraunhofer, ${ }^{12}$ factors such as intensification of stress, higher rates of ridge resorption, deep incisal notches, sharp changes in the denture base contours, and processing changes result in the fracture of the denture bases. In order to overcome this inherent disadvantage, various methods to strengthen the acrylic resin have been suggested.

In the studies done by Kurtz, ${ }^{13}$ Zhang et al. ${ }^{14}$ suggested that PEEK, which was being used in industries, has a potential for biomedical applications also. According to Brillhart and Botsis ${ }^{15}$ and Sobieraj and Rimnac, ${ }^{16}$ properties such as solvent resistance, biocompatibility, and modulus of elasticity which is same as that of the bone make PEEK a good candidate for medical and dental applications. Hence, PEEK can be thought to be a novel material to substitute PMMA, but few studies have been done to assess the mechanical behavior of PEEK when it has to be utilized as a denture base material. Zappini et al. ${ }^{17}$ did a study 
to assess the strength of five types of heat-activated denture base resins and concluded that although the strength of the denture base depends on the impact, it is not an ideal test for the prediction of the clinical function. The flexural strength is essential as it foresees the rigidness of the denture base material that is vital to maintain the integrity of the soft as well as hard tissues along with the accurate fit. Hence, this study evaluates and compares the flexural strength of PMMA and PEEK. When Chinchumnong et al. ${ }^{18}$ in their study did a comparison between 3- and 4-point bending tests for various dental polymers, they concluded that the values did not vary significantly, but the values obtained by 3-point bending test were higher. Alhareb ${ }^{19}$ compared the VHN values of unfilled PMMA with that of PMMA reinforced with NBR or ceramic fillers. He concluded that the VHN values did not significantly increase after the addition of fillers. Fraunhofer and Suchatlampong ${ }^{20}$ and Braun et al. ${ }^{21}$ compared the VHN for differently activated PMMA. It was found that the hardness values were greater for heat-activated PMMA than that of the other available differently activated PMMA. Hence, in the present study, an attempt was made to compare the $\mathrm{VHN}$ values of PMMA and PEEK.

The mean flexural strength of subgroup $A_{1}$ specimens, i.e., PMMA, was $84.05 \mathrm{MPa}$. The flexural strength values of Lucitone 199 were reported as $87.12 \mathrm{Mpa}$ by Machado et al. ${ }^{22}$ and $96.26 \mathrm{MPa}$ with a standard deviation of 5.76 by Dixon et al. ${ }^{23}$ Hence, the mean flexural strength of PMMA is in accordance with the previous researches done. In this study, the mean flexural strength of subgroup $A_{2}$ specimens was evaluated as $183 \pm 4.79$. Schwitalla et al. $^{24}$ reported the value of flexural strength of biomedical grade PEEK as $170.37 \pm 19.31$. Hence, the values obtained are similar to that of the previous studies. The VHN value of heat-activated PMMA subgroup $B_{1}$ in the present study is 19.12. In a study done by Ali et al. ${ }^{25}$ in 2007, where the VHN values of heat-activated and light-activated PMMA was compared, it was found that the VHN of heatactivated resin was $17 \pm 0.4$. Mathew and Ravishanka ${ }^{26}$ did a study in 2014 to compare the VHN of unfilled heat-activated PMMA with that of PMMA reinforced with glass fibers. The mean VHN values of unfilled PMMA were found to be $19.9 \pm 0.8$. In a study done by Duymus et al., ${ }^{27}$ it was found that the VHN value of heat-activated PMMA was 18.57. Hence, the result obtained in the present study is in accordance with that of the previous studies.

The mean hardness of subgroup $B_{2}$, PEEK specimens, was found to be 24.17. Goyal et al. ${ }^{28}$ evaluated PEEK using Vickers microhardness tester and reported it to be $24 \mathrm{kgf}$. The mean values of VHN for PEEK are similar to the previous studies. In the present study, the difference in the values of flexural strength of PMMA and PEEK was found to be highly significant $(p<0.001)$. The mean flexural strength of PEEK (183 MPa) was found to be greater than PMMA (84 MPa). A comparison was also done between the VHN of PEEK and PMMA, and a very high significant difference appeared between them. The VHN of PEEK (24.17) was evaluated to be greater than PMMA (19.12). The results obtained are in agreement with the study done by Muhsin et al. ${ }^{29}$ in which the flexural strength of the PEEK material was superior to that of the PMMA material. In addition to flexural strength, another important mechanical property was compared, i.e., hardness was also compared in this study, and it was observed that PEEK is significantly superior to PMMA with respect to hardness.

\section{Limitations and Recommendations}

The present study was not carried out in the oral environment to assess the properties of the materials. The properties after the bonding of the PEEK to the veneering material were not assessed. Further laboratory studies under oral conditions and with veneered PEEK samples should be carried out for accurate evaluation of the mechanical properties.

\section{Conclusion}

The mechanical properties like flexural strength and hardness values for PEEK are superior to that of PMMA, but further studies are required to evaluate and compare the other properties of these materials. Therefore, prosthesis fabricated with PEEK as a substructure may have a great impact on its prognosis and might also enhance the patient acceptability. Thus, this research is important as it puts forward a new material that can be successfully put to use clinically in order to overcome the drawbacks.

\section{ACKnOWLedgments}

Our sincere thanks to all those who helped in carrying out the study, especially to the staff of the Spectro Laboratory, Noida, for allowing us to use the machines and assisting us in carrying out the tests. We are grateful to the statistician for his advice on statistical methods employed in this study.

\section{References}

1. Khindria SK, Mittal S, Sukhija U. Evolution of denture base materials. J Indian Prosthodont Soc 2009;9(2):64-69. DOI: 10.4103/09724052.55246.

2. Tandon R. Denture base materials: from past to future. Indian J Dent Sci 2010;2:33-39.

3. Jagger RG. Effect of the curing cycle on some properties of a polymethylmethacrylate denture base material. J Oral Rehabil 1978;5(2):151-157. DOI: 10.1111/j.1365-2842.1978.tb01208.x.

4. Nejatian T, Johnson A, Noort RV. Reinforcement for denture base resin. Int J Adv Sci 2006;4:124-129. DOI: 10.4028/www.scientific.net/AST.49.124

5. Heimer S, Schmidlin PR, Roos M, et al. Surface properties of polyetheretherketone after different laboratory and chairside polishing protocols. J Prosthet Dent 2017;117(3):419-425. DOI: 10.1016/j.prosdent.2016.06.016.

6. Anusavice KJ. Phillips science of dental materials. 11th ed. W.B Saunders; 2003. p. 78-98.

7. Peyton FA. History of resins in dentistry. Dent Clin North Am 1975;19(2):211-222.

8. Yazdanie N, Mahood M. Carbon fiber acrylic resin composite: an investigation of transverse strength. J Prosthet Dent 1985;54(4):543547. DOI: 10.1016/0022-3913(85)90431-7.

9. Phoenix RD. Denture base materials. Dent Clin North Am 1996;40(1):113-120. DOI: 10.5005/jcdp-6-4-93

10. Meng TR, Latta MA. Physical properties of four acrylic denture base resins. J Contemp Dent Pract 2005;6(4):93-100.

11. Uzun G, Hersek N, Tincer T. Effect of five woven fiber reinforcements on the impact and transverse strength of a denture base resin. J Prosthet Dent 1999;81(5):616-620. DOI: 10.1016/s0022-3913(99)70218-0.

12. Beyli MS, Fraunhofer JA. An analysis of causes of fracture of acrylic resin dentures. J Prosthet Dent 1981;46(3):238-241. DOI: 10.1016/00223913(81)90206-7.

13. Kurtz SM. An overview of PEEK biomaterials. In: PEEK Biomaterials Handbook, Elsevier; 2012. p. 1-7.

14. Zhang Z, Breidt C, Chang L, et al. Wear of PEEK composites related to their mechanical performances. Tribol Int 2004;37(3):271-277. DOI: 10.1016/j.triboint.2003.09.005. 
15. Brillhart $M$, Botsis J. Fatigue crack growth analysis in PEEK. Int J Fatigue 1996;16(2):134-140. DOI: 10.1016/0142-1123(94)90103-1

16. Sobieraj MC, Rimnac. Fracture, fatigue, and notch behavior of PEEK. In: PEEK biomaterials handbook. Elsevier; 2012. p. 61-73.

17. Zappini G, Kammann A, Wachter W. Comparison of fracture tests of denture base materials. J Prosthet Dent 2003;90(6):578-585. DOI: 10.1016/j.prosdent.2003.09.008.

18. Chinchumnong, Stafford GD. Comparison of three- and four-point flexural testing of denture base polymers. Dent Mat J 1989;5(1):2-5. DOI: 10.1016/0109-5641(89)90082-1.

19. Alhareb AO, Akil H, Ahmad ZA. Impact strength, fracture toughness and hardness improvement of PMMA denture base through addition of nitrile rubber/ceramic fillers. Saudi J Dent Res 2017;8(1-2):26-34. DOI: 10.1016/j.sjdr.2016.04.004.

20. Fraunhofer $V$, Suchatlampong $C$. The surface characteristics of denture base polymers. J Dent 1975;3(3):105-109. DOI: 10.1016/03005712(75)90060-3.

21. Braun KO, Mello JAN, Rached RN, et al. Surface texture and some properties of acrylic resins submitted to chemical polishing. J Oral Rehabil 2003;30(1):91-98. DOI: 10.1046/j.1365-2842.2003.00997.x.

22. Machado C, Sanchez E, Azer SS, et al. Comparative study of the transverse strength of three denture base materials. J Dent 2007;35(12):930-933. DOI: 10.1016/j.jdent.2007.09.006.
23. Dixon DL, Ekstrand KG, Breeding LC. The transverse strengths of three denture base resins. J Prosthet Dent 1991;66(4):510-513. DOI: 10.1016/0022-3913(91)90514-w.

24. Schwitalla A, Spintig T, Kallage I, et al. Flexural behavior of PEEK materials for dental application. Dent Mater 2015;31:1377-1384. DOI: 10.1016/j.dental.2015.08.151.

25. Ali IL, Yunus N, Abu-Hassan MI. Hardness, flexural strength, and flexural modulus comparisons of three differently cured denture base systems. J Prosthodont 2008;17(7):545-549. DOI: 10.1111/j.1532849X.2008.00357.x.

26. Mathew MSK, Ravishanka KS. Vickers hardness and specific wear rate of polypropylene reinforced PMMA. Int J Sci Study 2014;2(3):71-75.

27. Duymus ZY, Ozdogan A, Ulu H, et al. Evaluation the Vickers hardness of denture base materials. Open J Stomatol 2016;6(4):114-119. DOI: 10.4236/ojst.2016.64014.

28. Goyal RK, Tiwari AN, Mulik UP, et al. Study on micro hardness, dynamic mechanical and tribological properties of PEEK/AI2O3 composites. J Appl Polym Sci 2008;110(6):3379-3387. DOI: 10.1002/ app.28925.

29. Muhsin SA, Hatton PV, Johnson A, et al. Determination of polyetheretherketone (PEEK) mechanical properties as a denture material. Saudi J Dent Res 2019;31(3):382-391. DOI: 10.1016/j. sdentj.2019.03.005. 